\title{
ESTUDO DA RESISTÊNCIA À CORROSÃO ENTRE VERGALHÕES COM DIFERENTES MICROESTRUTURAS FRENTE AOS ÍONS CLORETOS *
}

\author{
Matheus de Lima Vieira ${ }^{1}$ \\ Francisco Alberto Marreiros da Rocha da Silva² \\ Mauro Andrés Cerra Flórez ${ }^{3}$ \\ Marcelo José Gomes da Silva ${ }^{4}$ \\ Walney Silva Araújo ${ }^{5}$
}

\section{Resumo}

Os vergalhões são produzidos por meio do processo de laminação a quente. No processo em estudo há duas rotas distintas de produção. Previamente ao processo de laminação a quente, uma rota utiliza a etapa de reaquecimento via forno, e a outra utiliza o produto semi-acabado de aço vindo diretamente do processo de solidificação. Ao estabelecer um comparativo entre as rotas, as microestruturas obtidas apresentam algumas diferenças. O objetivo desse trabalho é avaliar como as diferenças entre as microestruturas influenciam na resistência à corrosão por cloretos. Para isso foram realizados ensaios de polarização potenciodinâmica anódica e espectroscopia de impedância eletroquímica em solução de $\mathrm{NaCl}$, simulando os efeitos do íon $\mathrm{Cl}^{-}$presente na atmosfera marinha. A partir das curvas obtidas nos ensaios eletroquímicos, foi possível observar que as propriedades de corrosão são semelhantes para ambos os processos.

Palavras-chave: Corrosão por cloretos; Vergalhões; Laminação.

\section{STUDY OF CORROSION RESISTANCE BETWEEN REBARS WITH DIFFERENT MICROSTRUCTURES BY CHLORIDE IONS}

\begin{abstract}
The rebar are produced by hot rolling process. In the process studied here there are two distinct production routes. Prior to the hot rolling process, one route uses the reheat step through the furnace, and the other uses the semi-finished steel product directly from the solidification process. When establishing a comparison between the routes, the obtained microstructures show some differences. The objective of this work is to evaluate how the differences between the microstructures influence in the resistance to corrosion by chlorides. For this, anodic potentiodynamic polarization and electrochemical impedance spectroscopy tests were performed in $\mathrm{NaCl}$ solution, simulating the effects of $\mathrm{Cl}^{-}$ion present in the marine atmosphere. From the curves obtained in the electrochemical tests, it was possible to observe that the corrosion properties are similar for both process.
\end{abstract}

Keywords: Chloride Corrosion; Rebars; Hot Rolling.

\footnotetext{
Graduando em Engenharia Metalúrgica, Universidade Federal do Ceará

2 Bacharel em Metalurgia, Mestrando em Ciência dos Materiais, Universidade Federal do Ceará, Assistente Técnico, Aciaria, Gerdau Aços Brasil

3 Bacharel em Metalurgia, Mestrando em Ciência dos Materiais, Universidade Federal do Ceará

4 Doutor em Engenharia Nuclear, Professor Adjunto, Departamento de Engenharia Metalúrgica e de Materiais, Universidade Federal do Ceará

5 Doutor em Engenharia Metalúrgica e de Materiais, Professor Associado, Departamento de Engenharia Metalúrgica e de Materiais, Universidade Federal do Ceará.
} 


\section{INTRODUÇÃO}

O concreto armado é um material composto de concreto e armadura de aço, na forma de barras (vergalhões), e devido a sua larga aplicação se faz necessário a avaliação da sua durabilidade. A corrosão de armaduras de aço utilizadas como reforço em concreto armado tem sido reconhecida mundialmente como um sério problema, visto que esse fenômeno gera custos com reparos em estruturas que foram danificadas pelos efeitos corrosivos, e adicionalmente as perdas econômicas, a segurança das pessoas é também afetada, uma vez que o colapso de estruturas pode oferecer risco à vida da população [1-2].

A corrosão das armaduras é um processo eletroquímico que ocorre naturalmente, conduzindo a formação de óxidos e hidróxidos de ferro com volume muito superior ao volume do metal de origem. Este aumento de volume cria tensões internas no concreto que levam ao surgimento de fissuras, destacamento do cobrimento, perda de aderência entre o concreto e a armadura e perda de seção da armadura, podendo levar à instabilidade e ao colapso de uma edificação [3].

Os vergalhões são fabricados pelo processo de laminação a quente, onde o produto semi-acabado de aço (tarugo), é mantido a altas temperaturas para que possa ser conformado, dando forma final ao produto. Geralmente o tarugo de aço antes de ser laminado, passa por um processo de reaquecimento realizado em fornos, que utilizam combustíveis fósseis como fonte de energia, combustíveis esses que oneram custos para a fabricação dos vergalhões. Recentemente, como alternativa a rota de fabricação com uso de fornos de reaquecimento, surgiu a prática de laminar o aço beneficiando-se das altas temperaturas que este possui imediatamente após o processo de solidificação. Porém, ao estabelecer o comparativo entre as rotas de produção, há algumas diferenças na microestrutura do aço, proporcionadas pelas diferentes condições de tratamento térmico oferecidas por cada processo.

A partir dessas diferenças microestruturais, foi realizado um estudo comparativo de resistência à corrosão entre vergalhões do mesmo tipo de aço, obtidos pelas duas rotas de fabricação, frente aos íons cloretos, principais responsáveis pelos efeitos danosos em armaduras de concreto armado.

\subsection{Corrosão por Cloretos}

O íon cloreto é um dos mais significantes contaminantes naturais, presente principalmente na atmosfera marinha que tem um papel fundamental no processo corrosivo de aços estruturais. Esses íons influenciam na cinética de corrosão, assim como na morfologia e na característica protetiva dos filmes de produtos de corrosão, onde altas concentrações de cloreto promovem a formação de produtos responsáveis por acelerar o processo corrosivo [4].

Os cloretos são transportados através dos poros e micro trincas presentes no concreto por difusão ou por capilaridade da solução aquosa que é dissolvida, estes depassivam o filme de óxido que cobre o aço e aceleram a reação de corrosão. O ataque tem como ação inicial a corrosão da estrutura de aço, consequentemente danificando o concreto de suas vizinhanças. A propagação do processo corrosivo ocorre a uma taxa que depende da disponibilidade de oxigênio e água no cátodo. [5-6]. 
O processo corrosivo pode levar a uma redução na força de ligação entre as barras de aço e o concreto e a uma perda na área de seção transversal da barra, o que causa a perda da capacidade de carga da estrutura. Essa redução de área produz algumas falhas repentinas na estrutura, sem escoamento e sem indícios prévios [6].

\subsection{Processo de Laminação a Quente}

O processo de laminação a quente consiste na elevação de temperatura do aço para que este possa ser facilmente deformado. Uma das principais formas de elevar a temperatura do material, tornando-o adequado para o processo de laminação a quente é através do uso de fornos de reaquecimento, que constituem uma etapa intermediária entre os processos de lingotamento contínuo e laminação a quente. O processo de reaquecimento tem grande efeito no tamanho de grão da austenita e na uniformidade do tamanho de grão ao longo da seção do produto semi-acabado. Quanto maior a temperatura e o tempo de exposição, maiores serão as taxas de crescimento dos grãos [7-9].

Uma alternativa na produção de aço é a laminação a quente a partir do semi-acabado proveniente do processo de lingotamento contínuo, sem a necessidade de sofrer um processo de reaquecimento, onde o material é laminado diretamente a partir de sua estrutura bruta de fusão. A grande vantagem dessa prática é a economia de energia proporcionada devido à redução do uso de fornos de reaquecimento. Na Figura 1 temos uma representação esquemática do processo de laminação a quente de vergalhões, mostrando a diferença entre as rotas de produção com e sem o uso da etapa de reaquecimento.

\section{Lingotamento Contínuo}

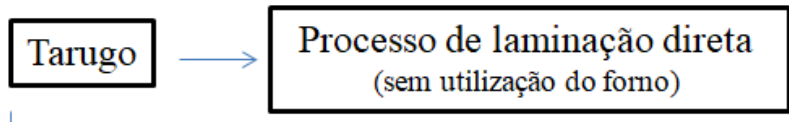

Processo com etapa de Reaquecimento

Figura 1 - Diagrama esquemático representando o processo de laminação a quente com e sem o uso da etapa de reaquecimento prévia aos passes de laminação. Fonte: Própria do autor

A temperabilidade dos aços (a profundidade de endurecimento) depende do tamanho de grão da austenita prévia a laminação e da presença de elementos de liga. Se a austenita apresentar tamanho de grão grande, a transformação perlítica levará mais tempo para ocorrer, favorecendo assim a formação de estrutura martensítica [10].

Após o último passe de laminação, as barras laminadas passam por um sistema controlado de resfriamento por água, sofrendo um rápido e intensivo resfriamento de sua superfície. Nessas condições, a estrutura da camada superficial sofre transformação de fase de austenita para martensita, com posterior revenimento da mesma devido ao reaquecimento imposto pelo núcleo à superfície da barra. Por fim, ocorre resfriamento ao ar, e a temperatura da superfície se iguala a do núcleo (cerca de $100 \stackrel{\circ}{\circ}$ ou menos), quando o resfriamento do vergalhão é concluído. Então o núcleo acaba de se transformar, sendo constituído de uma microestrutura de perlita + ferrita [11]. 


\section{MATERIAIS E MÉTODOS}

Para a realização da caracterização microestrutural e dos ensaios eletroquímicos foram cortadas amostras da seção transversal de vergalhões com 8 $\mathrm{mm}$ de diâmetro, laminados em ambos os processos (com e sem etapa de reaquecimento). O aço utilizado neste estudo para a fabricação dos vergalhões é classificado como aço baixo carbono, com composição química similar ao aço SAE 1020.

\subsection{Caracterização Microestrutural}

As amostras para análise microestrutural foram lixadas em lixas de carbeto de silício com granulometrias de 100, 200, 320, 400, 600 e 1200, então foram polidas em alumina coloidal com granulometria de $1 \mu \mathrm{m}$ e $0,05 \mu \mathrm{m}$. $\mathrm{O}$ ataque das amostras foi realizado em solução de nital $2 \%$ (ácido nítrico + álcool etílico) para a revelação dos contornos de grão da microestrutura. Para a aquisição das micrografias óticas, foi utilizado o microscópio ótico da marca Zeiss® modelo AXIO Imager.M2m.

\subsection{Ensaios Eletroquímicos}

Para fins de comparação entre a resistência à corrosão de barras laminadas por ambas as rotas de produção, foram realizados ensaios de polarização potenciodinâmica anódica em triplicata e espectroscopia de impedância eletroquímica. Utilizando como eletrólito solução de $\mathrm{NaCl} 0,1 \mathrm{M}$, eletrodo de referência de $\mathrm{Ag} / \mathrm{AgCl}$ e contra-eletrodo de platina. Antes do início do ensaio de polarização, foi realizada a medida do potencial de circuito aberto durante $1 \mathrm{~h}$, tempo esse suficiente para a estabilização do potencial de corrosão ( $E_{c o r r}$ ), a partir do qual se iniciou o ensaio, ou seja, a aplicação de sobretensões em relação ao $E_{\text {corr, neste }}$ caso no sentido anódico, com taxa de varredura de $1 \mathrm{mV} / \mathrm{s}$, varredura esta interrompida quando a corrente atingiu o valor de $1 \mathrm{~mA}$.

Os ensaios de espectroscopia de impedância eletroquímica foram realizados com tempos de imersão no eletrólito de $1 \mathrm{~h}, 5 \mathrm{~h}, 9 \mathrm{~h}$ e $24 \mathrm{~h}$. O tempo de monitoramento do potencial de circuito aberto foi de $1 \mathrm{~h}$ antes do início da primeira medida, e de 15 minutos antes do início das demais medidas. A faixa de frequências utilizadas foi de $40 \mathrm{KHz}$ a $6 \mathrm{mHz}$, com aquisição de 7 pontos por década de medição, aplicando-se tensão com amplitude de $10 \mathrm{mV}$.

Para a realização dos ensaios eletroquímicos, foi utilizado o potenciostato da marca Metrohm®, modelo PGSTAT302N, acoplado ao computador dotado do software Nova $\AA$ v.1.11 para registro dos dados.

\section{RESULTADOS E DISCUSSÃO}

\subsection{Microestrutura}

Para apresentação dos resultados, serão utilizadas as seguintes siglas para cada processo: FR - para o processo de laminação com a utilização de forno de reaquecimento; LD - para o processo de laminação direta de tarugos vindos do lingotamento contínuo. 
Com o intuito de comparar as diferenças entre as barras laminadas com e sem o uso da etapa de reaquecimento, foram realizadas análises microestruturais do produto semi-acabado e do produto final. A Figura 2 mostra as micrografias dos tarugos, onde foram realizadas medições de tamanho de grão utilizando o método do intercepto presente na norma ASTM E112. Observou-se um maior tamanho de grão no tarugo que passou pelo forno de reaquecimento devido ao tempo considerável de exposição sob temperaturas entre $1060^{\circ} \mathrm{C}$ (aproximadamente 60 minutos) e $1200^{\circ} \mathrm{C}$ (aproximadamente 30 minutos).

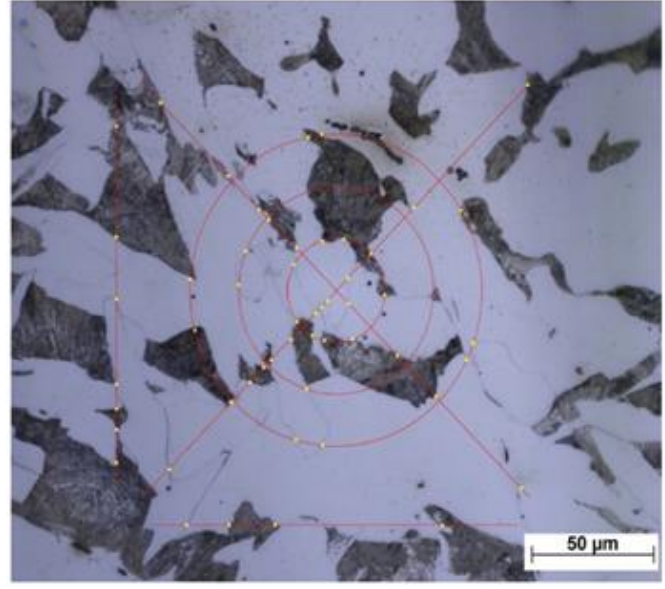

(a)

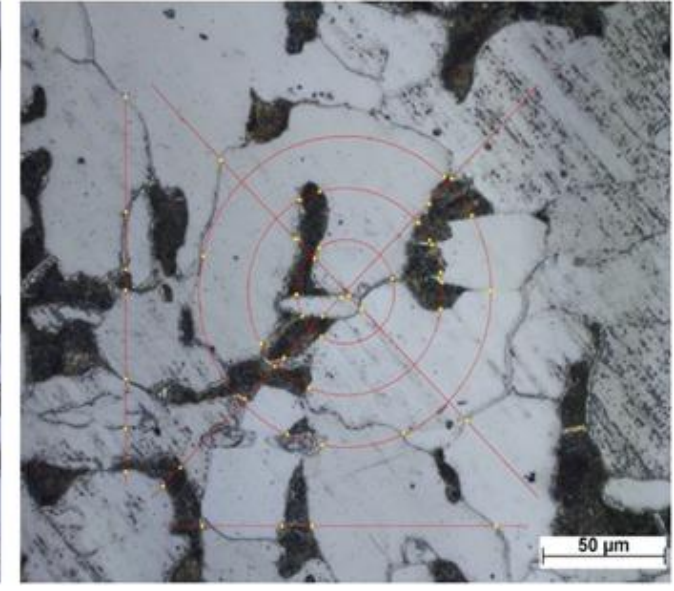

(b)

Figura 2 - Micrografias óticas prévias a laminação (Tarugos): (a): Processo FR. Tamanho de grão ASTM G 6 (dmédio = 44,9 $\mu \mathrm{m})$; (b): Processo LD. Tamanho de grão ASTM G 7 (dmédio $=31,8 \mu \mathrm{m})$. Aumento 500x. Fonte: Própria do autor.

A estrutura prévia a laminação que apresentou o maior tamanho de grão (com o uso do forno de reaquecimento) proporcionou ao produto final, maiores tamanhos de grãos na região central formada por perlita e ferrita, indicado na Figura 3, e a formação de maior quantidade de martensita na região superficial da barra, indicada na Figura 4, onde a espessura dessa camada foi medida a partir de macrografias dos vergalhões (região superficial mais escura), com o auxílio do software ImageJ®. A Tabela 1 mostra os valores estimados das medidas realizadas em quatro pontos distintos de cada amostra e a média obtida para esses valores.

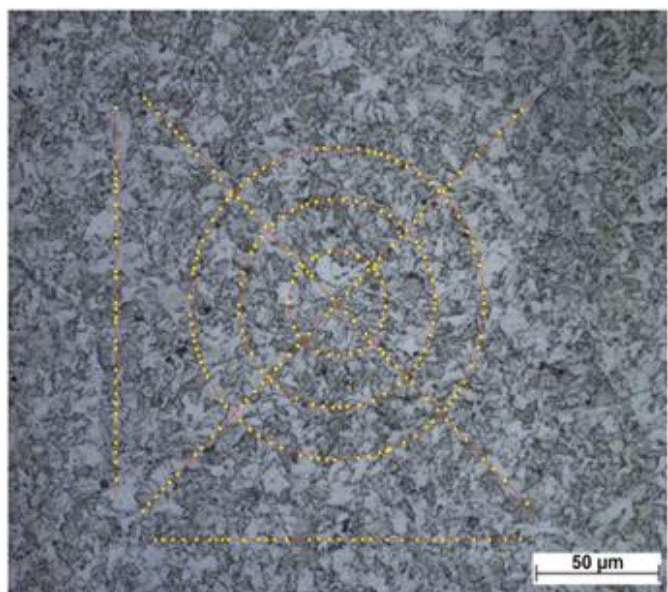

(a)

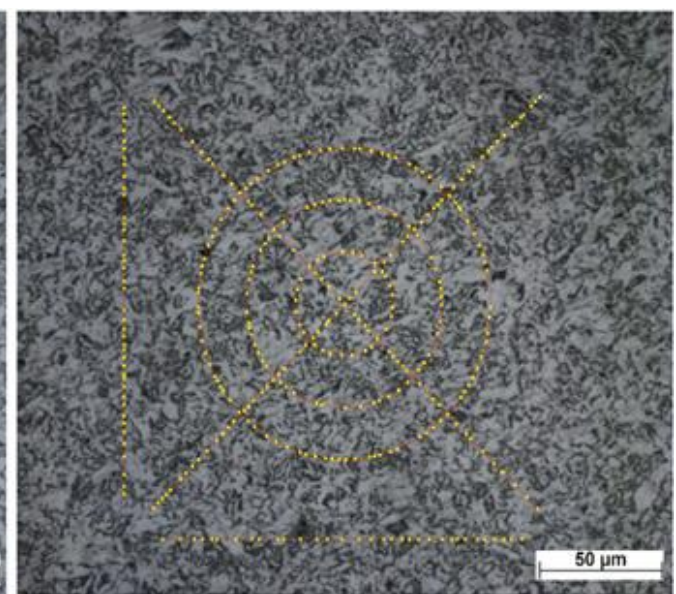

(b)

Figura 3 - Micrografias óticas da região central dos vergalhões: (a): Processo FR. Tamanho de grão ASTM G 12 (dmédio = 5,6 $\mu \mathrm{m}$ ); (b): Processo LD. Tamanho de grão ASTM G 12,5 (dmédio = 4,7 $\mu \mathrm{m}$ ). Aumento 500x. Fonte: Própria do autor. 


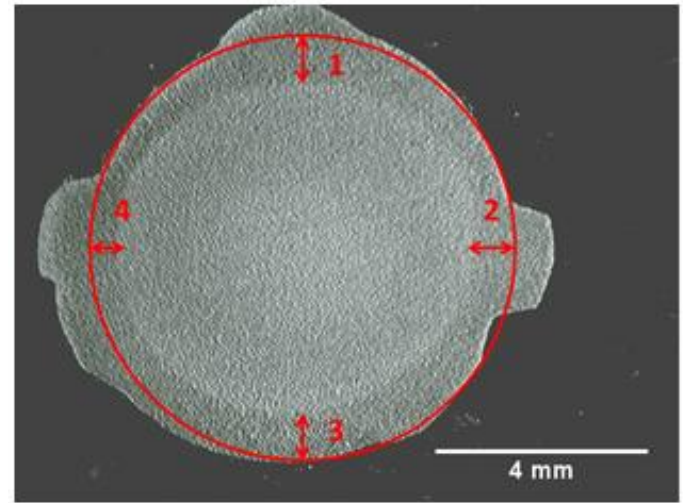

(a)

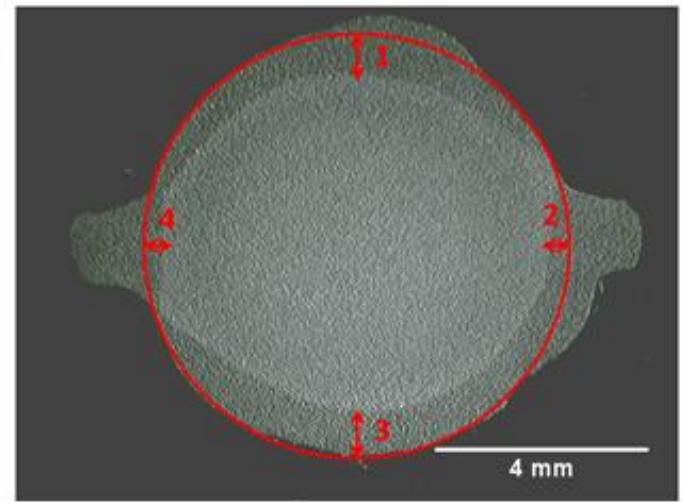

(b)

Figura 4 - Macrografias da seção transversal do vergalhão laminado, indicando os pontos onde foram realizadas as medidas da espessura da camada de martensita: (a) Processo FR. (b) Processo LD. Fonte: Própria do autor.

Tabela 1 - Espessura da camada de martensita. Fonte: Própria do autor.

\begin{tabular}{ccc}
\hline & PROCESSO FR & PROCESSO LD \\
\hline PONTO & ESPESSURA (mm) & ESPESSURA (mm) \\
1 & 0,937 & 0,772 \\
2 & 0,881 & 0,393 \\
3 & 0,839 & 0,828 \\
4 & 0,601 & 0,393 \\
\hline MÉDIA & $\mathbf{0 , 8 1 5}$ & $\mathbf{0 , 5 9 7}$ \\
\hline
\end{tabular}

\subsection{Ensaios de Corrosão}

A curva comparativa de polarização anódica entre as amostras obtidas pelos dois processos apresentada na Figura 5 , mostrou que o potencial de corrosão ( $\left.E_{\text {corr }}\right)$ para ambas as amostras foi semelhante, e que não houve região característica de passivação em nenhum dos casos.

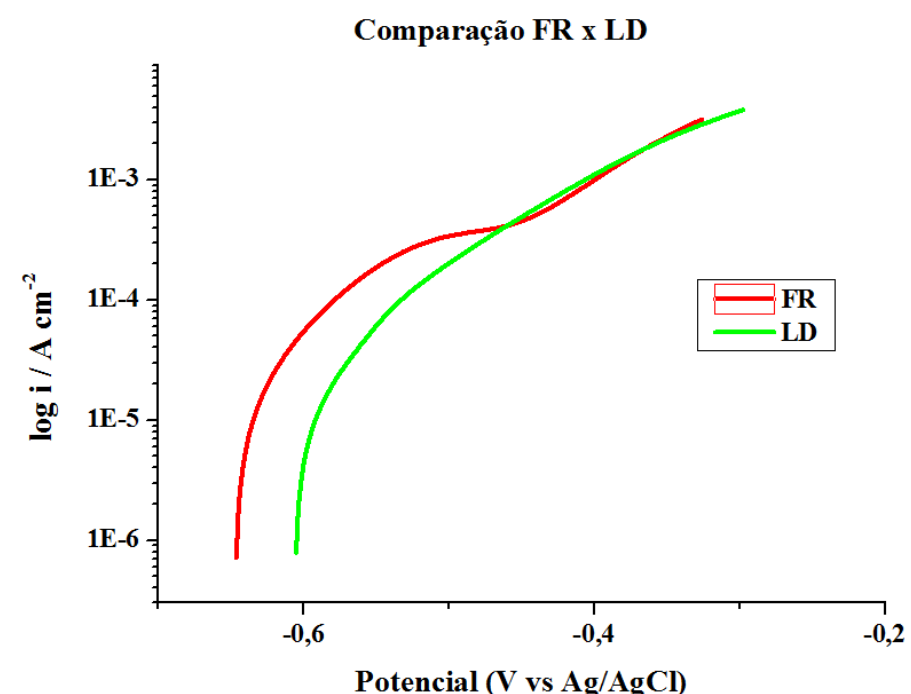

Figura 5 - Curva de polarização anódica comparativa entre as amostras FR e LD.

Fonte: Própria do autor. 
Os resultados dos ensaios de espectroscopia de impedância eletroquímica para ambas as amostras são mostrados na Figura 6, que representam os diagramas de Nyquist, estes possuem único semi-círculo capacitivo, o que significa que o processo corrosivo é controlado principalmente por transferência de carga [12].

Com o aumento do tempo de imersão na solução de $\mathrm{NaCl} 0,1 \mathrm{M}$ observou-se para ambas as amostras a tendência de diminuição do arco capacitivo, indicando uma diminuição na resistência à corrosão do aço com o tempo. Comparando as amostras FR e LD, observou-se que os diâmetros dos semi-círculos da amostra FR são maiores que o da amostra LD, o que significa que a resistência à corrosão da amostra FR é maior do que da amostra LD.
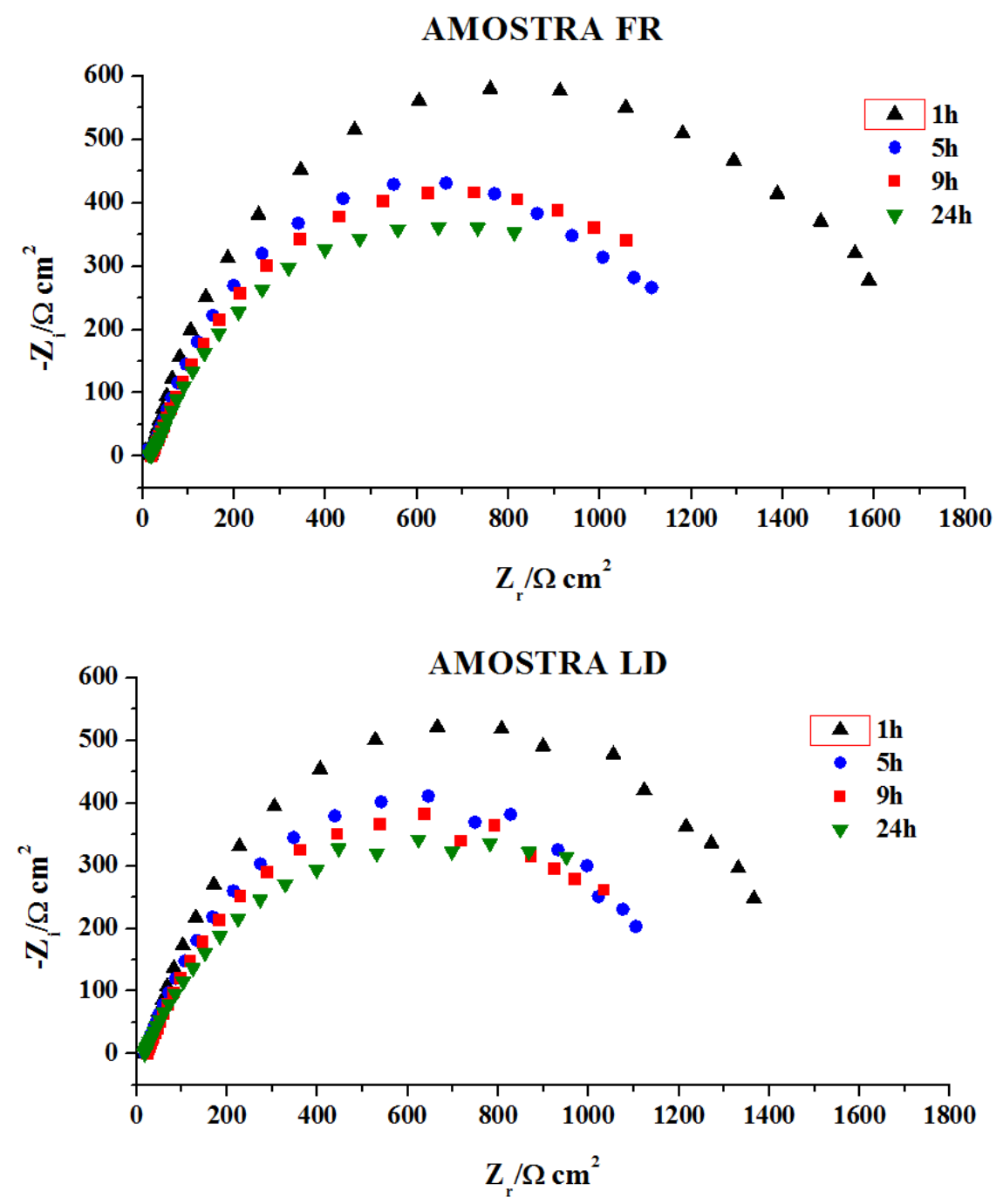

Figura 6 - Diagramas de Nyquist com as medidas realizadas após diferentes tempos de imersão para as amostras FR e LD. Fonte: Própria do autor.

O gráfico apresentado na Figura 7 foi obtido com o auxílio do software Nova® v.1.11 e representa a soma dos valores de resistência à polarização e resistência da solução, $R p+R s\left(\Omega . \mathrm{cm}^{2}\right)$, obtidos nos ensaios de impedância em função do tempo de imersão das amostras na solução. Observou-se que a soma de ambas as resistências das amostras FR foi inferior apenas no tempo de imersão de $1 \mathrm{~h}$, e superior nos demais tempos de imersão, confirmando a tendência que os 
diagramas de Nyquist já haviam indicado, ou seja, as amostras FR possuem resistência à corrosão ligeiramente superior as amostras LD.

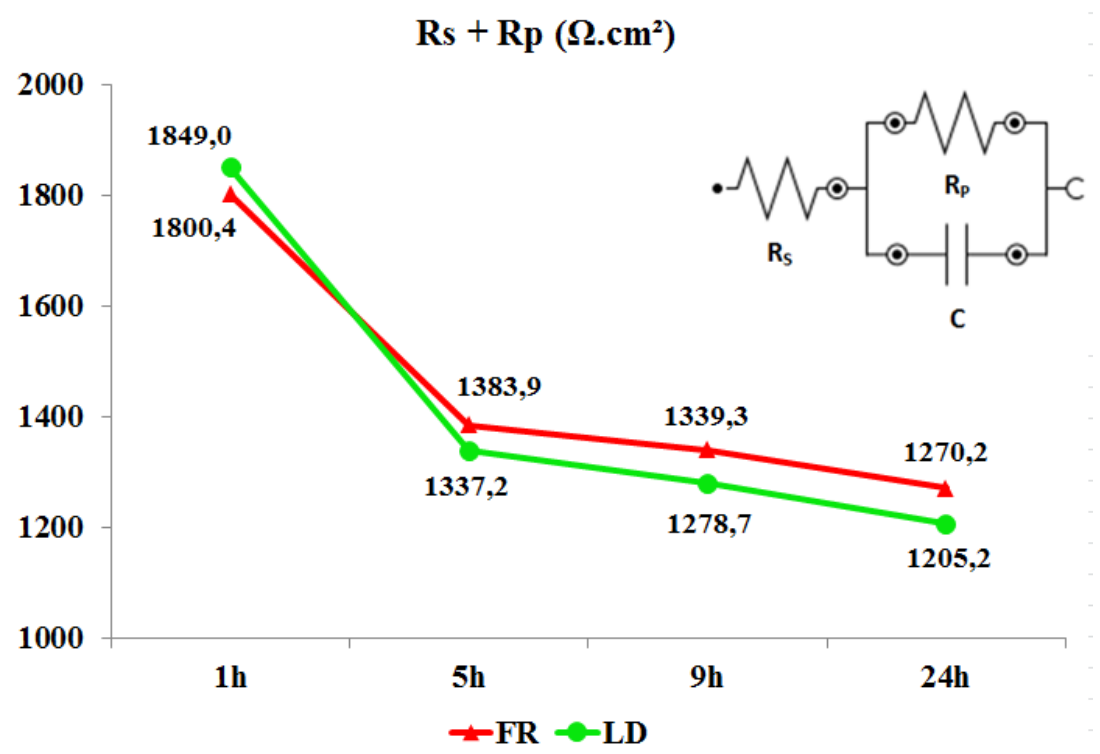

Figura 7 - Gráfico Rs + Rp $\left(\Omega . \mathrm{cm}^{2}\right)$ x Tempo de Imersão antes das medidas de Impedância. Fonte: Própria do autor.

Os resultados dos ensaios eletroquímicos mostraram que as amostras FR (com etapa de reaquecimento prévia a laminação) apresentaram resistência à corrosão um pouco maior em relação às amostras LD. A barra LD possui menor tamanho de grão na região central da barra (região perlítica e ferrítica com maior área na seção transversal) e menor quantidade de martensita formada superficialmente.

A relação entre tamanho de grão e taxas de corrosão ainda não foi completamente determinada. Em [13] foram reunidos diversos trabalhos relacionados a esse tópico e os materiais foram separados em duas classes, uma que apresenta baixas taxas de corrosão $\left(\leq 10 \mu \mathrm{A} / \mathrm{cm}^{2}\right)$ e outra com taxas de corrosão acima desse valor. A densidade de contornos de grão ditam as taxas de condução do filme de óxido para valores baixos (passivos), então espera-se que uma estrutura com grãos refinados seja mais resistente a corrosão. $\mathrm{Na}$ ausência de um filme de óxido, tais como em taxas de dissolução $>10 \mu \mathrm{A} / \mathrm{cm}^{2}$, uma redução no tamanho de grão provavelmente aumentará a reatividade e consequentemente a taxa de corrosão. Em termos de resistência à corrosão a utilidade do refino de grãos para redução das taxas de corrosão está confinada a materiais os quais são capazes de formar um filme passivo mais estável.

Conforme observado nos resultados obtidos para as curvas de polarização, não houve região de passivação nestas curvas e as taxas de corrosão obtidas para ambas as amostras foram maiores que $10 \mu \mathrm{A} / \mathrm{cm}^{2}$, indicando que o refino de grão nesse caso afeta a resistência à corrosão, fato esse que foi observado ao compararse a estrutura perlítica de ambas as amostras, onde a amostra LD com menor tamanho de grão na região central da barra (perlita + ferrita) apresenta menor de resistência à corrosão.

A resistência à corrosão de um material com duas fases normalmente é menor do que a de um material com única fase. Em [14] foi citado que a estrutura de 
perlita/ferrita fina apresenta melhores resultados em termos de corrosão generalizada comparada com a estrutura martensítica revenida, relatando que as taxas de corrosão diminuem com 0 aumento da fração de ferrita. Este comportamento é atribuído ao fato de que a ferrita, com maior teor de $\mathrm{Fe}$ do que a martensita, age como ânodo, enquanto a martensita com alto teor de carbono age como cátodo. Em [15] relata-se que a ferrita é menos nobre que a martensita, e que a taxa de dissolução anódica é maior para menores frações de ferrita (menor área anódica).

Outro fato citado por [16] é que a resistência à corrosão é afetada pelo nível de tensões internas na microestrutura. Sabendo que a martensita possui maior nível de tensões internas em relação à perlita/ferrita, quanto menor a quantidade de martensita na estrutura, maior a resistência à corrosão.

A Figura 8 apresenta 0 aspecto superficial das amostras, onde podemos observar que 0 ataque superficial dos íons cloreto sobre o aço foi levemente mais agressivo na amostra do processo LD, o que corresponde aos resultados obtidos nos ensaios eletroquímicos. Nessa figura são mostrados também os elementos presentes na superfície do aço, identificados através da técnica de EDS, onde se observou a presença de oxigênio, ferro e cloro, indicando a formação de óxidos na superfície, associados ao ataque dos íons $\mathrm{Cl}^{-}$.
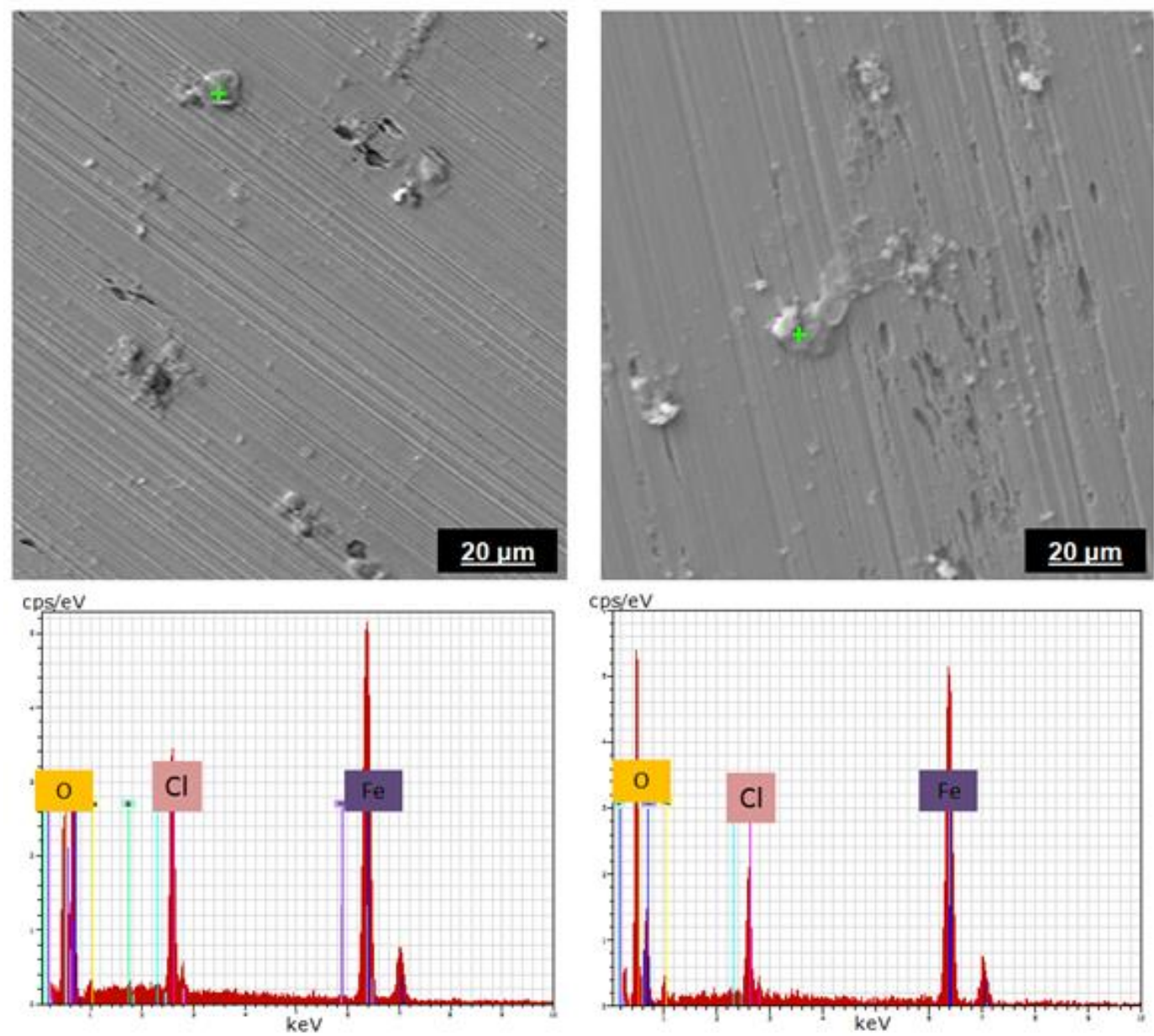

Figura 8 - Análise por EDS dos vergalhões após o ensaio de polarização anódica. (a): Processo FR; (b): Processo LD. Aumento 1000x. Fonte: Própria do autor. 
A partir dos resultados obtidos nas curvas de impedância eletroquímica, pode ser observado que nesse caso, o efeito do tamanho de grão da microestrutura exerce maior influência na resistência à corrosão do que a quantidade da martensita presente no vergalhão. O vergalhão com menor resistência à corrosão, no caso o proveniente do processo LD, possui menor tamanho de grão e ao mesmo tempo menor quantidade de martensita formada ao longo da seção. Portanto o efeito benéfico da menor quantidade de martensita na resistência à corrosão foi sobreposto pelo efeito danoso causado pela estrutura refinada de grãos.

\section{CONCLUSÃO}

A análise comparativa entre vergalhões laminados com o uso da etapa de reaquecimento e vergalhões laminados diretamente vindos do lingotamento contínuo mostrou que as barras laminadas com o uso do forno de reaquecimento (barras FR) apresentaram resistência à corrosão ligeiramente melhor, a partir dos resultados obtidos nos ensaios eletroquímicos de polarização anódica e espectroscopia de impedância eletroquímica em solução de $\mathrm{NaCl} 0,1 \mathrm{M}$. A melhor resistência à corrosão das barras FR deve-se ao fato de que estas possuem maior tamanho de grão na região central (região que ocupa a maior área na seção transversal da barra) e consequentemente menor área de contorno de grão, que torna o material menos reativo, reduzindo as suas taxas de corrosão.

Então os vergalhões laminados diretamente (LD) além de proporcionar redução no custo com energia de reaquecimento durante o processo, possuem resistência à corrosão, embora um pouco menor, comparável com relação aos vergalhões laminados com uso da etapa de reaquecimento (FR), frente aos efeitos dos íons cloreto.

\section{Agradecimentos}

Ao Departamento de Engenharia Metalúrgica e de Materiais e ao Programa de Pós-Graduação em Engenharia e Ciência de Materiais da Universidade Federal do Ceará, em especial ao Laboratório de Caracterização de Materiais - LACAM e ao Laboratório de Pesquisa em Corrosão - LPC, pelo uso de suas instalações para a realização desta pesquisa.

A Gerdau Aços Brasil - Unidade Cearense, pelo fornecimento de informações e amostras relacionadas aos processos em estudo.

\section{REFERÊNCIAS}

1. OLIVEIRA, M. C. C. "EFEITO DA ADIÇÃO DE CAL EM ARGAMASSA NA RESISTÊNCIA À CORROSÃO DE ARMADUUAS DE AÇO CARBONO E GALVANIZADAS", 124 f. Dissertação (Mestrado) - Programa de Pós-graduação em Engenharia Química, Escola de Engenharia Química, Universidade Federal de Minas Gerais - UFMG, Belo Horizonte, 2013.

2. KELESTEMUR, O.; YILDIZ, S. "Effect of various dual-phase heat treatments on the corrosion behavior of reinforcing steel used in the reinforced concrete structures", Construction and Building Materials, v. 23, n. 1, p.78-84, jan. 2009. Elsevier BV. 
3. CARVALHO, L. G. S. "RESISTÊNCIA À CORROSÃO DOS AÇOS CA24 E CA50 FRENTE À AÇÃO DOS CLORETOS”, 159 f. Dissertação (Mestrado) - Curso de Mestrado em Engenharia Civil, Escola de Engenharia Civil, Universidade Federal de Goiás - UFG, Goiânia, 2014.

4. MA, Y.; LI, Y.; WANG, F. "Corrosion of low carbon steel in atmospheric environments of different chloride content", Corrosion Science, v. 51, n. 5, p.9971006, may. 2009. Elsevier BV.

5. APOSTOLOPOULOS, C. A.; PAPADAKIS, V. G. "Consequences of steel corrosion on the ductility properties of reinforcement bar", Construction and Building Materials, v. 22, n. 12, p.2316-2324, dec. 2008. Elsevier BV.

6. APOSTOLOPOULOS, C. A.; DEMIS, S.; PAPADAKIS, V. G. "Chlorideinduced corrosion of steel reinforcement - Mechanical performance and pit depth analysis", Construction and Building Materials, v. 38, p.139-146, jan. 2013. Elsevier BV.

7. NALAWADE, R.S. et al. "Simulation of hot rolling deformation at intermediate passes and its industrial validity", International Journal of Mechanical Sciences, v. 77, p.8-16, dec. 2013. Elsevier BV.

8. JANSTO, S. G. "Reheat Furnace Operational Parameters Affecting Hot Roll Quality of Microalloyed Long Products", International Conference on Metallurgy and Materials - METAL 2015, 24., 2015, Brno, Czech Republic. Tanger Ltd., 2015.

9. RYU, J. H. "Model for Mechanical Properties of Hot-Rolled Steels", 80 p. Thesis - Degree of Master of Science in the Graduate Institute of Ferrous Technology (computational Metallurgy), Department of Ferrous Technology (computational Metallurgy), Pohang University Of Science And Technology, Pohang, Korea, 2008.

10. CHIAVERINI, V. "Aços e Ferros Fundidos: Características gerais, tratamentos térmicos, principais tipos”, 7. ed. São Paulo: Associação Brasileira de Metalurgia, Materiais e Mineração, 1996.

11. ALVES FILHO, C. H. M.; MOURA, L. M.; TORRES, R. D. "Analysis of Tempcore Process: Microstructural Gradient Formation and Their Influence on the Final Mechanical Properties", In: International Congress of Mechanical Engineering, 19th, 2007, Proceedings. Brasília: ABCM, 2007.

12. NADY, H. et al., "Corrosion behavior and electrochemical properties of carbon steel, commercial pure titanium, copper and copper-aluminum-nickel alloy in 3.5\% sodium chloride containing sulfide ions", Egypt. J. Petrol. feb. 2016.

13. RALSTON, K. D.; BIRBILIS, N.; DAVIES, C. H. J. "Revealing the relationship between grain size and corrosion rate of metals", Scripta Materialia, v. 63, n. 12, p.1201-1204, dez. 2010. Elsevier BV.

14. AL-RUBAIEY, S. I.; ANOON, E. A.; HANOON, M. M. "The Influence of Microstructure on the Corrosion Rate of Carbon Steels", Eng. \&Tech. Journal, Baghdad, v. 31, p.1825-1836, jan. 2013.

15. REMMERSWAAL, T. "The influence of microstructure on the corrosion behaviour of ferritic-martensitic steel", $93 \mathrm{f}$. Thesis of Master Degree of Science, Delft University Of Technology, Delft, 2015.

16. CANDELÁRIA, A. F.; PINEDO, C. E. "Influence of the heat treatment on the corrosion resistance of the martensitic stainless steel type AISI 420", Journal of Materials Science Letters, v. 22, n. 16, p.1151-1153, 2003. Springer Nature. 